Universidad de Lima

Facultad de Comunicación

Carrera de Comunicación

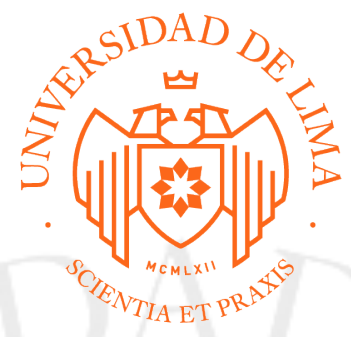

\title{
VEINTE AÑOS EJERCIENDO EL PERIODISMO POLÍTICO
}

Trabajo de Suficiencia Profesional para optar el Título Profesional de Licenciada en Comunicación

\section{Martha Cecilia Rosales Ferreyros \\ Código 861786}

\section{Asesor}

Pedro Ortiz Bisso

Lima - Perú

Setiembre 2019 


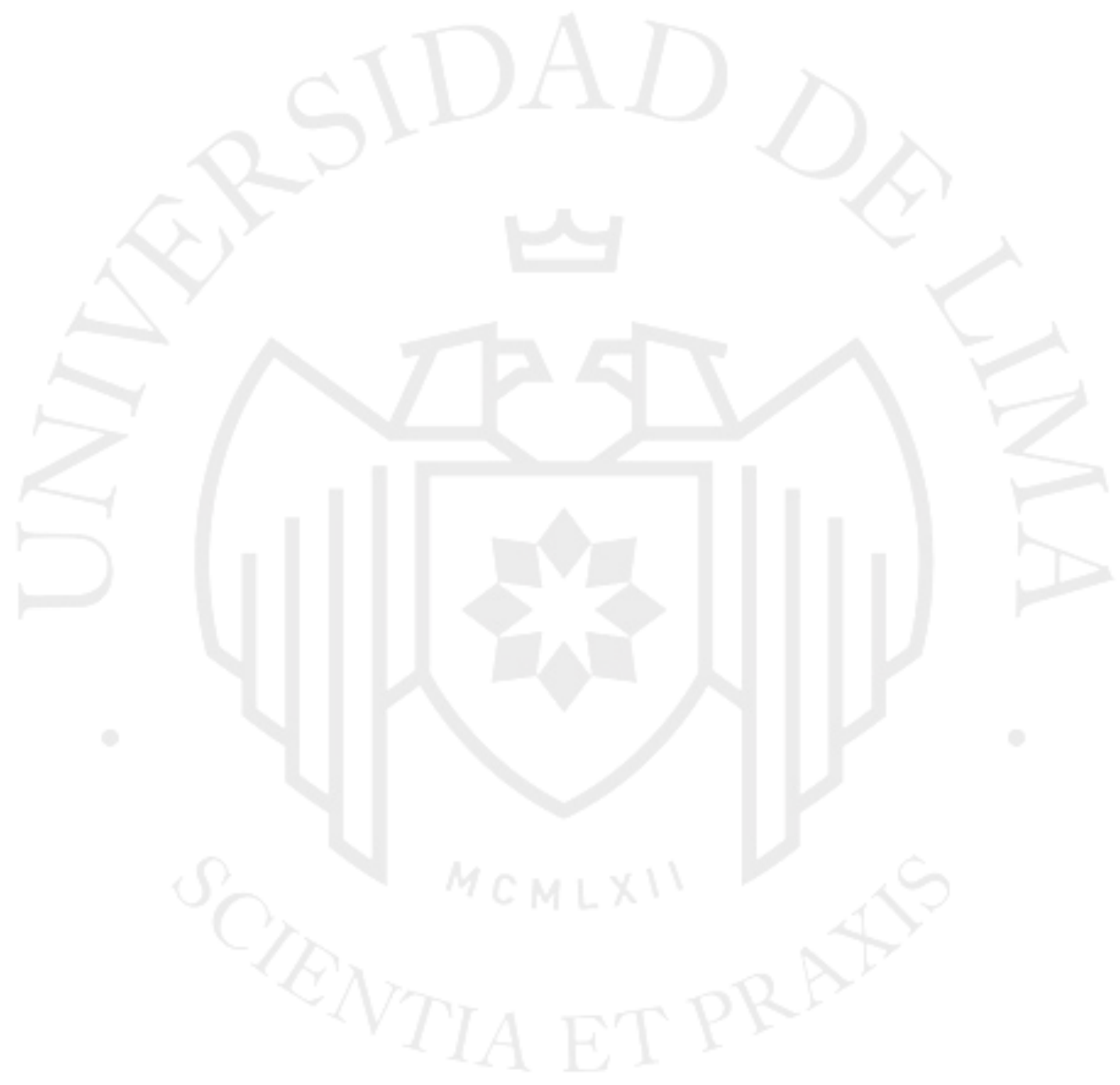


VEINTE AÑOS EJERCIENDO EL PERIODISMO POLÍTICO 


\section{ÍNDICE}

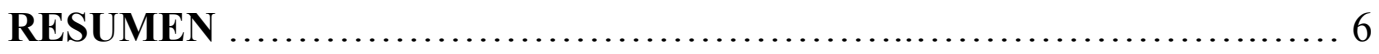

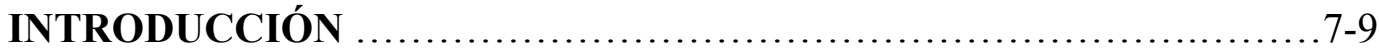

1. EXPERIENCIA PROFESIONAL .................................... 10-14

2. COMPETENCIAS PROFESIONALES ............................. 15

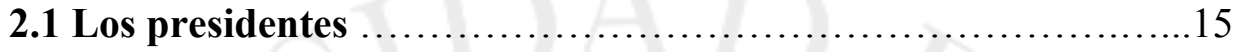

2.1.1 Alberto Fujimori .........................................15

-Momentos de terror........................................16

-El asesor Montesinos........................................16

-Rehenes del MRTA..........................................17

-De madrugada.......................................... 17

2.1.2 Valentín Paniagua ..........................................18

-Primera entrevista.......................................... 18

2.1.3 Alejandro Toledo ..........................................18

-La muerte de Anatolio...........................................19

-Presentación del informe de la Comisión de la Verdad ..............19

2.1.4 Alan García ......................................................19

-Una mujer de altas cualidades................................20

-Visita a su Santidad Benedicto XVI............................20

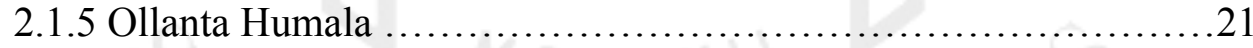

-Evaluación del Plan de Gobierno 'La Gran Transformación' .......22

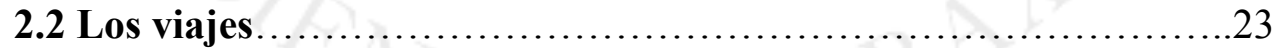

-La vuelta al mundo........................................ 23

-Seguridad extrema..........................................24

-Porqué no te callas.........................................24

-Entrevista a Hugo Chávez...................................24

-El avión parrandero........................................25

-Terremoto en Pisco..........................................25

2.3 El litigio marítimo Perú-Chile...................................26

-Suplemento La Haya ............................................26 
-La Fase Oral................................................27

-Perú y Ecuador sellaron sus límites marítimos....................28

-La lectura de la sentencia.....................................28

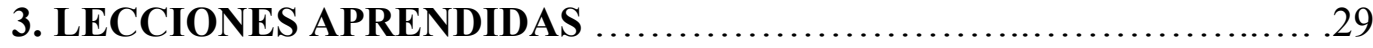

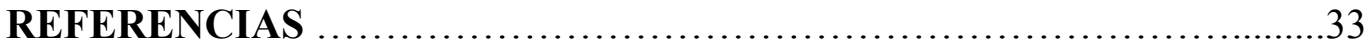

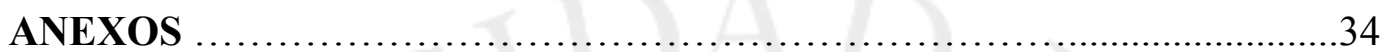




\section{RESUMEN}

Periodista con más 20 años de experiencia en cobertura, análisis y presentación de la realidad política. Trabajé en la Sección Política del Diario El Comercio entre abril de 1995 y junio del 2015. Los primeros años trabajé en el turno noche, por lo que reportaba las sesiones en el Congreso. Poco a poco empecé a especializarme en la cobertura del Poder Ejecutivo. Seguí las actividades públicas, evalué los discursos y realicé análisis de la gestión de gobierno de cinco presidentes: Alberto Fujimori, Valentín Paniagua, Alejandro Toledo, Alan García y Ollanta Humala. Además, me involucré en la cobertura de las actividades de la Cancillería y en el análisis de la política exterior del Perú (agenda bilateral, regional y multilateral).

El seguimiento de las actividades presidenciales y de la cancillería me llevó a ser testigo de múltiples cumbres presidenciales como APEC, Alianza del Pacífico, ALC-UE, Cumbres Iberoamericanas, Unasur etc., así como visitas de Estado y oficiales a diferentes países.

Pero la cobertura que considero la más importante de mi carrera periodística es el seguimiento y análisis del Litigio Marítimo entre el Perú y Chile. A ese tema le dediqué diez años de mi vida profesional, incluida la etapa preliminar a la presentación de la demanda ante la corte de La Haya, la cobertura en la corte (etapa oral y lectura de sentencia) y la ejecución del fallo. 


\section{INTRODUCCIÓN}

Soy periodista desde que tengo uso de razón. Mi primer acercamiento al periodismo fue como corresponsal escolar del Diario El Comercio cuando estaba en cuarto de secundaria. La madre Teresa -una de las más temidas del colegio donde estudiaba- me animó a inscribirme como corresponsal y me llevaba en una vieja camioneta jeep desde el colegio, en Chaclacayo, hasta el centro de Lima. Era casi un viaje interprovincial. Empecé a ver los frutos cuando aparecieron algunos artículos míos en el diario. Uno de los mejores recuerdos de aquella época es que gané un concurso de corresponsales del Diario y recibí el premio de manos del Director de El Comercio Don Aurelio Miró Quesada Sosa: un diccionario de la Real Academia. Su discurso sobre la responsabilidad que entrañaba ser periodista me marcó. Me prometí que regresaría algún día y seria periodista del Decano. Para ello tenía que estudiar y elegí la Facultad de Comunicaciones de la Universidad de Lima. Recuerdo entre mis profesores a Mario Razzeto, Rosario Sheen, Óscar Quezada y Julio Hevia. Mi vocación por el periodismo se acentuó durante esos años universitarios.

Escribir se fue transformando en una necesidad. Tom Wolfe, y lo que se denominó el Nuevo Periodismo, fue uno de los autores que me marcó. En mis 20 años de ejercicio periodístico he podido usar algunas de las pautas de su trabajo, como describir la realidad con minuciosidad y con emoción y presentar crónicas con un inicio, un desarrollo y un final. En suma, utilizar -cuando la ocasión lo permitía- algunas de las técnicas y recursos de la literatura en mis notas.

Hice prácticas en el diario Página Libre, de Guillermo Thorndike, y en la revista Oiga, en la sección Cultura.

Al finalizar mis estudios una de mis primeras oportunidades laborales se abrió en un canal de televisión. Ingresé al noticiero de Canal Nueve gracias a la convocatoria de una de mis profesoras de la Universidad, Rosario Sheen. 
El periodismo televisivo me gustó. No había reporteros especializados. Un día podía entrevistar a un político y al otro a un futbolista en el Estadio Nacional, y de paso recibir 'piropos' de grueso calibre de los aficionados apostados en las tribunas populares.

Corría por entonces el año 1992, una época en la que el terrorismo se dejaba sentir en Lima. Trabajaba en el turno de noche y el jefe de informaciones tenía que elegir qué atentado o matanza cubrir porque éstas se multiplicaban. A veces no importaba el número de víctimas sino el rango de las personas asesinadas. Éramos muy pocos en el turno nocturno.

Mi pareja en aquel momento no estaba de acuerdo en que fuera periodista. "Es muy arriesgado", "Te pagan una miseria" o "No necesitas trabajar" eran frases que repetía constantemente intentando convencerme de que me dedicara a otra cosa. Pocos meses después de mi ingreso al canal mi madre falleció, por lo que emocionalmente no estaba preparada para seguir afrontando las terribles escenas que, noche a noche, se producían en Lima debido a los actos terroristas.

Recuerdo especialmente un atentado en la comisaría de Villa El Salvador. Partimos raudamente alrededor de las nueve de la noche y el chofer asignado, conocido como 'Charapa', literalmente voló al lugar, por lo que fuimos los primeros en llegar. Todavía se escuchaban balazos y gritos a pocos metros de la comisaria que ardía en llamas. Había un apagón total. Mi camarógrafo y yo bajamos de la unidad y se acercaron corriendo dos militares que a gritos nos decían: "No se acerquen". No tuvieron mejor idea que empezar a disparar al piso para hacernos retroceder. Reconozco que entré en pánico y regresé a la camioneta. Poco después, decidí dejar el canal.

Me refugié en el mundo administrativo. Llegué a ser la administradora de la agencia más importante de una AFP de reciente creación. La rutina estaba asegurada. Mis contactos con el periodismo no se diluyeron gracias a Rosario Sheen, quien me propuso ser su jefa de prácticas del curso Introducción al Periodismo en mi alma mater.

La Universidad de Lima se convirtió en mi refugio para no desligarme de la carrera que amaba. Meses después le pedí ayuda y consejo a Rosario porque sentía que la rutina del 
trabajo administrativo me asfixiaba. Necesitaba hacer periodismo. Gracias a ella llegué, entonces, al Decano para una entrevista con el entonces editor de Política Juan Paredes Castro. Entré a prueba a la sección. Recuerdo mi primera comisión. Tenía que ir al Jurado Nacional de Elecciones, a pocas cuadras del diario. Le pregunté en la puerta de El Comercio a mi colega y hoy entrañable amigo Jorge Saldaña dónde quedaba La Colmena. Sonrió y me dijo con ojos sorprendidos: “¿Mamacita, no sabes dónde queda La Colmena?". Así, perdida en las calles del centro de Lima, comencé una aventura que duró 20 años. 


\section{EXPERIENCIA PROFESIONAL}

En abril de 1995 inicié lo que ha sido la experiencia más fructífera de mi carrera.

Entré a prueba con otras dos personas al Decano. Había pedido licencia sin goce de haber en el trabajo administrativo que tenía en ese momento. Libreta, lapicero y grabadora se convirtieron en objetos imprescindibles en mi cartera. La rutina desapareció de mi vida. Todos los días conocía gente nueva -humildes o poderosos- e iba a sitios de difícil acceso.

Al llegar al diario lo primero que hacia era revisar el cuadro de comisiones. Allí la coordinadora en ese entonces Rossana Echeandía establecía junto con el editor de la Sección Juan Paredes Castro qué actividades y temas debían ser cubiertos y a qué periodista se le asignaba la comisión. Por la tarde en la reunión de editores se definía qué espacio tendría cada nota en la edición impresa del día siguiente.

Al inicio trabajaba en el turno de noche. Mis primeras comisiones me llevaron al Congreso: largas sesiones plenarias y de comisiones parlamentarias.

Poco a poco empecé a ir con más frecuencia a Palacio de Gobierno para cubrir las actividades públicas -al inicio vespertinas o nocturnas- de Alberto Fujimori, quien ya ejercía su segundo mandato. De aquellos años, recuerdo haber caminado por muchos cerros de Lima. La caravana larguísima de vehículos de seguridad y de los medios a veces tenía problemas para avanzar por las empinadas trochas.

Luego llegaron los viajes al interior del país. Una de mis primeras experiencias fue en pleno Fenómeno de El Niño de 1997.

Eran aproximadamente las 10 de la noche. Cumplía mi turno nocturno ("el periodismo se hace de noche", me decían mis jefes, y efectivamente muchas de las informaciones que se publicaban al día siguiente se rehacían o completaban en la noche, ya que la coyuntura política en el Perú era -y continúa siendo- muy volátil). 
Volviendo a aquella noche, me llamaron y dijeron: "Hay un cupo para El Comercio en el avión presidencial. Te vas a Piura. El presidente supervisará los daños generados por el Fenómeno de El Niño". Y así fue. Partí directamente del diario, sin muda de ropa, con poca plata y unos zapatitos de cuero blancos que, obviamente, no eran para la ocasión.

Al día siguiente, muy temprano, mi simpático calzado quedó sumergido en un barro de medio metro de altura en uno de los poblados afectados. Horas más tarde, me informaron que nos quedaríamos una noche más, así que tuve que comprar lo indispensable para seguir. Zapatos de faena, para empezar.

Así de sorpresiva se volvió mi vida.

En los primeros años no era fácil transmitir la información. Conseguir una computadora y tener tiempo para sentarme a escribir era, muchas veces, un lujo. En ocasiones no me quedaba otra que avanzar mis notas a mano en el helicóptero o avión asignados para la cobertura, y transmitirlas luego por teléfono. A veces, mis días empezaban a las cinco o seis de la mañana en el Grupo Aéreo Número Ocho. Usualmente, el avión presidencial nos transportaba a una ciudad en la que nos esperaba un helicóptero. A lo largo del día podíamos visitar hasta tres localidades. Poblados remotos donde una persona común solo podía llegar caminando, a lomo de bestia o por río.

En cada lugar escuchaba y grababa los discursos con atención porque a veces ahí estaba la noticia. Otras veces lo noticioso surgía en las declaraciones que se daban al final del día o en algún incidente como el del helicóptero presidencial (Ver anexo 1). También me llamaban de Lima y me decían: "Cecilia, ha ocurrido esto en el Congreso o en el Poder Judicial; por favor, indaga al respecto. Busca un pronunciamiento del presidente".

Si tenía suerte, llegaba al diario al promediar las siete u ocho de la noche a escribir la nota del día. Si el cansancio no me derrumbaba, avanzaba en el avión presidencial las ideas principales.

"Cecilia, tu nota", me repetía constantemente el editor de cierre. "Solo faltas tú, apúrate". Tales eran las frases que me atormentaban al llegar a Lima. Felizmente, en esa época el cierre de edición era a la medianoche. Teníamos el lujo de no compartir la imprenta con otros medios del Grupo. Sin embargo, debo reconocer que para un 
periodista que hace notas a diario la hora del cierre puede llegar a ser una tortura. "Pásamela como esté", me gritaba a veces mi editor de cierre cerca de las 12, y la corregíamos en pantalla contra el reloj. De lo contrario, aparecíamos en el temido reporte de tardanzas al día siguiente.

La mayor parte de mis viajes se produjeron durante la presidencia de Alejandro Toledo. Fue un frenesí de viajes de ida y vuelta a provincias o de varios días al extranjero. En comparación con su antecesor, Alan García viajó poco dentro del Perú. Decidió no usar el avión presidencial, el cual había sido rebautizado como 'avión parrandero' (Ver anexo 16). Pero como enviada especial del Diario realicé varios viajes al extranjero durante su segundo mandato. Ollanta Humala sí frecuentó un poco más las provincias, pero decidió no llevar a los periodistas en la aeronave presidencial.

Desde el inicio en Palacio de Gobierno sentí el peso de la responsabilidad de ser la periodista designada del diario más importante del país. Me di cuenta de que no era como en el Congreso, donde tenías decenas de congresistas y asesores buscándote para dar información.

En Palacio de Gobierno la única fuente autorizada para declarar era el mandatario y, eventualmente, los ministros. No existía la figura del vocero de prensa. Los trascendidos eran un elemento válido pero peligroso. Me acostumbré a trabajar con fuentes confiables. Pero para considerarlas dentro de esa categoría se requería tiempo y paciencia.

Al inicio cotejaba con una o dos más lo que me revelaba alguna de ellas en medio de conversaciones informales, en las caminatas de los viajes, en las esperas del avión o del helicóptero, en medio de ceremonias oficiales o en largas conversaciones informales telefónicas ejerciendo el 'cuchareo'. Siempre he sido un poco desconfiada de lo que me dicen a la primera. Poco a poco te vas dando cuenta de cuáles son las fuentes confiables. Para eso se necesita que un periodista vaya continuamente a una sola fuente, como fue en mi caso.

Me convertí en la periodista del Decano asignada a Palacio de Gobierno. 
Los cinco presidentes que he seguido, como es natural, iniciaban su mandato con gente nueva, con sus equipos de confianza, y se tomaban unos meses en nombrar a las cabezas en decenas de cargos públicos disponibles al inicio de cada gobierno.

Por ello, muchas de mis fuentes confiables desaparecían cuando llegaba a Palacio de Gobierno un nuevo jefe de Estado. Había que volver a empezar. Además, durante los años de permanencia de un presidente los cargos se renovaban en cualquier momento, por lo que he tenido decenas de fuentes confiables. Son muy pocas las que me han acompañado a lo largo de toda mi carrera, en puestos clave pero de menor rango, las cuales nunca revelaré.

Yo usaba una teoría que bauticé como los círculos del poder. Después de todo, qué es el poder si no tener la capacidad de influir en el otro. En mi caso, establecía en primer lugar quién tenia a disposición la oreja del presidente.

Todos los gobernantes han tenido un círculo de poder íntimo, reducido, con el que tomaban las decisiones más importantes. Era difícil llegar a ese grupo. Me acostumbré, por ello, a empezar con las indagaciones preliminares en los otros círculos: los equipos de confianza de los que tenían a disposición la oreja del presidente. Cuando conseguía alguna información relevante de este segundo o tercer círculo llamaba a las cabezas y les decía: "Estoy escribiendo sobre este tema pero me falta corroborar algunos datos".

Normalmente la reacción era: “¿Cómo te has enterado?”."Yo no revelo mis fuentes”, era mi respuesta habitual. "En realidad solo lo estoy llamando porque estoy poniendo el punto final a mi nota y no quiero equivocarme", añadía. Era una pequeña estrategia porque a veces solo tenia una oración, que felizmente me completaba la persona que tenía al otro lado del teléfono para que no fuera a dar información incorrecta.

Las fuentes oficiales de Palacio de Gobierno siempre se han esforzado por intentar marcar la agenda noticiosa, pero en mi caso usualmente buscaba tener información propia o un ángulo noticioso distinto. Disfrutaba revisar el diario al día siguiente y ver que mi nota era única y valiosa.

Las notas que más disfrutaba escribir eran aquellas en las que podía poner un poco de emoción, de pasión. Pero no era posible hacerlo todos los días. 
Sobre todo en los viajes al extranjero. Usualmente enviaba una nota más formal con lo noticioso del día y aparte una crónica en la que contaba alguna situación pintoresca (Ver anexos 9,11,12,13,14,16). 


\section{COMPETENCIAS PROFESIONALES}

Son incontables los momentos relevantes que he vivido como periodista de El Comercio. He tenido el privilegio de ser testigo de algunos momentos que han marcado la historia reciente de nuestro país.

La siguiente es una reducida selección de coberturas periodísticas agrupadas en tres grandes temas: Los presidentes, los viajes y el Litigio Marítimo Perú-Chile. La fecha que aparece es la de publicación.

\subsection{Los Presidentes}

Cinco son los mandatarios que he tenido el privilegio de seguir como periodista de El Comercio. Lamentablemente, solo uno -Valentín Paniagua, ya fallecido- está libre de cuestionamiento. No es el caso de Alberto Fujimori (condenado por corrupción y preso), ni de Alejandro Toledo (preso) o de Ollanta Humala, quienes enfrentan graves cargos por corrupción. Alan García se suicidó cuando iba a ser detenido por graves acusaciones de corrupción.

Al margen de la situación actual de estos cinco jefes de Estado, la cobertura que realicé de sus actividades públicas durante 20 años me ha dejado grandes recuerdos. Aquí una apretada selección de las coberturas más relevantes -por la huella histórica que dejarony otras que me marcaron como periodista.

\subsubsection{Alberto Fujimori}

Yo no empecé como la periodista titular en Palacio de Gobierno en representación de El Comercio. Inicialmente iba a cubrir las actividades presidenciales vespertinas. Poco a poco empecé a ir con más asiduidad a Palacio, e incluso realicé algunos viajes con Fujimori. Era un presidente que lucía amable y risueño con los periodistas, y en la 
época que lo conocí ya había aprendido a lidiar con la prensa. Ya no era el mandatario que había llegado a Palacio sin saber hacer política.

Separaba a los periodistas en tres grupos para las conferencias de prensa: prensa escrita, prensa radial y televisiva. Empezaba por la prensa escrita, con la que se demoraba más ya que realizábamos preguntas con mayor detalle. Luego venía la radial y acababa con la televisiva. En ese momento, de tanto repetir el mensaje, él ya sabía como editarlo y hacerlo mas corto para un medio como el televisivo. Incluso tenia manejo de cámara y sabía mover las manos para enfatizar lo que le interesaba.

Tres anécdotas son las que más recuerdo de la época de Alberto Fujimori.

-Momentos de terror: Fui testigo de un incidente en el vuelo de un helicóptero que transportaba al presidente y a los periodistas de Juliaca a Santa Lucía. El piloto perdió el control debido a la presencia de humo en la aeronave. Recuerdo haber gritado de terror junto a otros colegas al sentir que la nave caía sin control al vacío. Felizmente, tras algunos minutos la nave logró ser estabilizada. El copiloto resultó herido.

Recuerdo, de esos instantes de angustia, cómo un miembro de seguridad del presidente lo tomó del brazo e hizo que se pusiera de pie. Él se sentaba siempre en el primer asiento al lado de la puerta. Luego me comentó que lo hizo porque pensaba saltar de la nave y protegerlo con su vida cuando estuviéramos cerca del suelo. Tras aterrizar, fue muy difícil que luego de que revisaran la nave volviéramos a subir para seguir con la agenda porque estábamos a 58 kilómetros de Juliaca. No hubo tiempo ni siquiera para angustiarse. (Anexo 1) (15 de setiembre 1996)

-El asesor Montesinos: Vladimiro Montesinos aparece sorpresivamente por primera vez al lado del jefe de Estado en una conferencia de prensa. Fujimori, como ya era su costumbre, hizo pasar a uno de los salones de Palacio a los periodistas de prensa escrita para responder las preguntas de esta. Grande fue nuestra sorpresa al encontrar al esquivo y cuestionado asesor Montesinos al lado de altos mandos del Ejército explicando la Operación Siberia, un plan que había logrado-según aseguraron- capturar a traficantes de armas que iban a abastecer a las FARC. Fue una conferencia extraña. Solo intervinieron Fujimori y Montesinos. Los ministros de Defensa, Interior y el jefe 
del SIN de ese entonces permanecieron en silencio. Lo más llamativo fue cómo Fujimori justificó y elogió la gestión de Montesinos como asesor y cómo durante toda la conferencia los altos mandos militares no dijeron nada. (Anexo 2) (22 de agosto del 2000)

-Rehenes del MRTA: La noche en la que los terroristas del MRTA tomaron 300 rehenes en la embajada del Japón estaba de guardia en El Comercio. Faltaba poco para partir a casa cuando a través de la radio empezamos a recibir información de lo ocurrido. Rápidamente se tomó la decisión de realizar una edición especial en la que participaron varios de los periodistas que estábamos esa noche en la redacción. Se hizo una edición especial contra el reloj en la que hice un aporte (Anexo 3) (18 de diciembre de 1996)

-De madrugada: Congreso destituye a tres integrantes del Tribunal Constitucional por oponerse a la re-reelección de Fujimori (Ley de Interpretación Auténtica).

Llegué al Congreso en la tarde y me quedé hasta el día siguiente al promediar las siete de la mañana. El fujimorismo tenía la mala costumbre de aprobar leyes polémicas o tomar medidas cuestionables de madrugada. La destitución de los magistrados se produjo alrededor de las tres de la mañana, pero la sesión siguió con otras polémicas medidas. En el diario cerraron la edición y en realidad pude haberme ido a casa, pero decidí quedarme. Recuerdo haber tomado aguadito con los colegas en la cafetería del Congreso, mientras esperábamos que Víctor Joy Way, presidente del Legislativo en esa época, se dignara levantar la sesión.

Me fui a casa cuando los reporteros de televisión hacían sus transmisiones matutinas en vivo contando sobre la larga jornada. Lamentablemente ya no escribí una crónica para la edición del día siguiente debido a que el peso de la información ya estaba en reportar las reacciones a la cuestionable decisión. (Anexo 4) (29 de mayo de 1997) 


\subsubsection{Valentín Paniagua}

\section{-Primera entrevista como presidente en ejercicio}

Paniagua casi no cumplió agenda pública y no tenia mayor contacto con los medios. Sin embargo accedió a darme una entrevista durante su mandato.

(Anexo 5) (22 de abril del 2001)

\subsubsection{Alejandro Toledo}

Una de las cosas que más recuerdo de Alejandro Toledo es "la hora Cabana". Rara vez se cumplía el horario de su agenda pública. También recuerdo las excusas y los grandes esfuerzos que tenía que realizar su equipo de confianza para apartarlo de la prensa cuando estaba en sus momentos de "relajo".

Al inicio no era muy claro en sus declaraciones, lo que le generó varios problemas. La excusa que se ponía era que pensaba en inglés y confundía las palabras al decirlas en castellano. No era un presidente que supiera hacer política, es decir, enviar los mensajes precisos en el momento adecuado. Su prioridad, al comenzar su mandato, estuvo más en lo económico y en la recomposición institucional luego del Fujimorismo, pero no sabía transmitirlo y explicarlo, al punto de que se decidió nombrar a un primer ministro político como Carlos Ferrero. Él tuvo que cumplir -en algunas ocasiones- la tarea de traductor de los mensajes presidenciales, luego de que varios sectores le pidieran al presidente que diera un paso al costado.

Toledo con la prensa era amable pero distante. Solo una vez en un momento de tensión por alguna nota publicada me dijo: “Cómo jodes Cecilia”... “¿Disculpe?”, repliqué yo con la ceja levantada. "Nada" dijo y se alejó rápidamente. Su esposa Eliane muchas veces nos miraba con enojo, como conteniéndose para no decir lo que pensaba.

Con Toledo los viajes al interior del país fueron innumerables. A tal punto que al regresar a Lima muchas veces buscaba un mapa para ver dónde había estado. El ruido, traqueteo e incomodidad de los vuelos en helicóptero y Antonov se volvió una constante en mi vida. 
-La muerte de Anatolio: El edecán del presidente Toledo le informa que su padre ha fallecido. Lamentablemente lo hace con el micrófono prendido en pleno escenario, por lo que la multitud escucha sus palabras (Anexo 6) ( 11 de noviembre del 2005)

\section{-Presentación del informe de la Comisión de la Verdad y Reconciliación (CVR).} Recuerdo que el respeto y simpatía por la CVR en esa época era muy alta, así que poner una sutil crítica a su titular Salomón Lerner por no calificar en ningún momento como terroristas a los miembros de Sendero Luminoso y afirmar que el informe equiparaba el accionar del terrorismo con el de las Fuerzas Armadas significó un intercambio de pareceres en la sección. Recuerdo que antes de partir a mi casa le dije a mi jefe: “Aquí dejo marcado en el discurso de Lerner y en el resumen del informe lo que sustenta las afirmaciones del texto. Si realizan cambios sustanciales a mi nota, por favor retiren mi crédito". Al día siguiente salió como la había planteado. (Anexo 7) (29 agosto del 2003)

\subsubsection{Alan García}

El ex presidente Alan García cerró por completo su círculo más íntimo de toma de decisiones. Tenía una segunda oportunidad después de un desastroso primer gobierno. Enviaba mensajes de que no decepcionaría a los peruanos y que buscaba dejar un legado de orgullo a sus hijos. Es por eso, en mi opinión, que hizo lo posible por cerrar cualquier posibilidad de que trascendieran rumores sobre su vida privada o errores de gestión como había ocurrido en su primer gobierno. Cuando empezó a comentarse sobre su sexto hijo zanjó el tema rápidamente y de motu propio.

García era un mandatario muy hábil políticamente. Tenía el don de la palabra, del mensaje preciso y oportuno y era diestro marcando la agenda noticiosa. Tenía olfato para captar algún tema de coyuntura que preocupara a la gente y fijar posición, evadiendo así los temas que no quería poner en agenda. Justamente era eso lo que más suspicacias me generaba. Fue un constante reto cubrir sus actividades. Intentar 
determinar dónde estaba el truco o la manipulación detrás de sus "bonitos discursos". Con la prensa era retador. Tenías que estar bien informada para hacerle preguntas porque le gustaba hacer repreguntas o pedir más detalles.

Viajó muy poco al interior del país y no llevaba a prensa en el avión presidencial. Intentó venderlo, sin éxito, porque consideraba que era una símbolo de la frivolidad del gobierno anterior. Así es que la cobertura de sus actividades fue básicamente en Lima. Asistía a inauguraciones, reuniones en diversos puntos y usualmente al terminar brindaba declaraciones. Le gustaba tener el monopolio de las primicias. Rara vez designaba a un ministro o funcionario para que diera una noticia importante. Los anuncios usualmente los daba él, a menos que fueron muy especializados de un sector específico.

-Una mujer de altas cualidades: Siempre comentaba que mi deber como periodista no era reportar sobre la vida privada de los presidentes. Mi labor era informar sobre sus actividades públicas, a menos que ellos decidieran ventilar alguna situación personal o que ésta tuviera trascendencia política. Esto es lo que ocurrió cuando el ex gobernante Alan García, frente a los rumores periodísticos que señalaban que tenía un hijo fuera del matrimonio, decidió zanjar el tema confirmándolo al lado de su esposa Pilar Nores.

Fue una situación impactante, tal como describo en la nota, sobre todo por la presencia de Nores, con una tristeza profunda en el rostro, al lado de su esposo. Cuando García utilizó la frase -en vivo y a nivel nacional- "una mujer de altas cualidades" para referirse a la madre de su sexto hijo me sentí apenada por Nores. Recuerdo que propuse que al tratarse de un tema personal delicado, la declaración del presidente debería ir textual y solo acompañada de una introducción que describiera lo ocurrido en Palacio. Así fue. (Anexo 8) (24 de octubre del 2006)

-Visita a su Santidad Benedicto XVI: "Señora Rosales esto es para usted. Estoy seguro de que lo va a valorar más", recuerdo que me dijo sin detener el paso el ex presidente García al salir de la biblioteca del papa Benedicto XVI mientras me entregaba una caja con un rosario que le había regalado el pontífice. Me quedé 
sorprendida, sobre todo porque el rosario era de cuentas negras. Me preguntaba por qué Su Santidad le habrá regalado un rosario negro. ¿Habrá sido un mensaje subliminal? Después de todo, el color negro se asocia a lo oscuro y negativo. Lo guardé un poco intrigada y preferí no pensar más en eso. Todavía lo guardo en algún cajón. (Anexo 9) (1 de diciembre del 2009)

\subsubsection{Ollanta Humala}

Había un recelo mutuo entre la prensa y Ollanta Humala al inicio de su gobierno. La campaña había sido dura y a pesar de que su mensaje se había alejado de posiciones anti sistema y se había acercado al centro, un halo de incredulidad lo rodeaba.

Desde un inicio sentí el toque militar en sus relaciones con la prensa, en el sentido de orden, jerarquía, horarios que debían cumplirse, etc. Su equipo lo "cuidaba" de la prensa porque era notorio que todavía no tenía "manejo de medios" (esquivar preguntas, cambiar la agenda noticiosa, dar explicaciones convincentes sobre un tema, hablarle a la gente y no a los periodistas, etc) y su experiencia política era reducida.

Al inicio confundía los mensajes o no era claro. Poco a poco empezó a tomar confianza en su relación con los medios. Pero decidió mantenernos lejos. Usaba el avión presidencial, pero no convocaba a los periodistas en helicópteros o Antonov a zonas alejadas, por lo que las coberturas se dificultaron. Los corresponsales suplieron muchas coberturas que se completaban en Lima.

Los equipos oficiales de transmisión de información fueron reforzados, y enviaban noticias e imágenes supervisadas a todos los medios. 


\section{-Evaluación del Plan de Gobierno del humalismo: La Gran Transformación}

Mi jefe Juan Paredes Castro se me acercó una mañana y me dijo: “Cecilia, necesito que revises esto (entregándome mas de 190 páginas impresas). Es el Plan de Gobierno que ha presentado el candidato Ollanta Humala al Jurado Nacional de Elecciones. Mañana quiero ver la nota".

Pasé saliva y empecé a revisar el mamotreto. Usualmente yo no seguía las actividades de los candidatos pero en época electoral la cobertura en Palacio decaía. No era tan noticioso seguir al personaje que estaba de salida. Es por eso que me encargaron esa tarea, que no fue nada fácil. No terminé ese día. Llevé el bodoque de papel a casa y en la noche seguí marcando lo que me llamaba la atención. Recuerdo haber pensado: "Esto ya lo he visto antes". Empecé a buscar el Plan de Gobierno que habían presentado en la elección anterior, en el 2006, y ¡Bingo! Había párrafos muy similares. Así es que la tarea se me complicó. ¡Estaba literalmente comparando dos mamotretos contra el reloj!

Al día siguiente, como a la una de la tarde, mi jefe me dice: "Cecilia, y cual es el ángulo". Recuerdo que contesté un poco fastidiada que ese documento lo habían elaborado durante meses decenas de intelectuales que apoyaban a Humala, y a mí solo me daban dos días para revisarlo, que necesitaba tiempo. "Déjenme parir por favor", recuerdo que grité un poco ofuscada. "Déjenme parir" era la frase que usaba cuando en más de una ocasión venían a apurarme para que entregara mi nota o para que dijera cual era el ángulo que estaba trabajando. Las similitudes con el Plan del 2006 fueron parte fundamental de lo que se publicó. La nota de la Gran Transformación la "parí" cerca de la medianoche y marcó un punto de quiebre en la campaña de Humala. Poco después, el candidato anunciaba un cambio en algunos puntos del mismo a través de un compromiso denominado Hoja de Ruta. (Anexo 10) (25 de marzo del 2011) 


\subsection{Los viajes}

Los viajes al exterior para seguir las actividades de los presidentes fueron una fuente inacabable de hechos extraordinarios. Eran agotadores por los cambios de horarios, pero especialmente por las largas horas que debíamos pasar en el avión presidencial. La aeronave solo tenía seis horas de autonomía de vuelo debido a que sus tanques de gasolina eran pequeños. Eso obligaba a que la ruta de vuelo incluyera ciudades remotas y poco conocidas para recargar combustible. Literalmente subíamos y bajábamos cada dos por tres, como gaviotas que suben y bajan. Puedo decir que he dado la vuelta al mundo en el avión presidencial. Los periodistas convocados por medio teníamos un cupo en el avión, pero los gastos en cada ciudad corrían a cargo del centro de trabajo de cada uno. Usualmente la comitiva de periodistas no se alojaba en el hotel del mandatario sino en otro cercano.

La cobertura periodística en el exterior normalmente se prestaba para desarrollar una nota formal con la noticia pura y dura del día, pero también para escribir crónicas que describían de manera coloquial alguna situación pintoresca que hubiera ocurrido. La siguiente es una apretada selección de algunos de esos viajes y las crónicas que escribí.

\section{-La vuelta al mundo:}

El primer viaje del presidente Alejandro Toledo en el avión presidencial fue literalmente una vuelta al mundo. Pasamos por Guayaquil (Ecuador), Acapulco (México), Los Ángeles (EEUU), Anchorage (Alaska, EEUU), Petropavlosvk (Rusia) y Shangái (China). Pero de regreso el presidente decidió cambiar la ruta para extender su visita a España por lo que tuvimos que pasar por Hong Kong, algún punto de Siberia (Rusia), Moscú (Rusia), Madrid (España), Islas Canarias (España), Fortaleza (Brasil) y finalmente Lima. 
Los momentos pintorescos del viaje los plasmé en tres crónicas, además de escribir diversas notas con la información más formal. Los cuestionamientos llegaron luego de que reportara a través de una crónica que el jefe de Estado había invitado a sus amigos y a la novia de uno de sus ministros al avión, y que la gira incluía paradas turísticas.

-De Guayaquil a Shangái (20 de octubre del 2001) (Anexo 11)

-Cambios en la ruta de regreso (23 de octubre del 2001) (Anexo 12)

-Seguridad extrema: Reunión Toledo-Bush en Shangái. (APEC) : Había pasado apenas 40 días de las terribles escenas del 11 de setiembre en Nueva York, y el presidente de Estados Unidos, George W. Bush, que le había declarado la guerra al terrorismo se encontraba en Shangái participando en la Cumbre de APEC. El presidente Toledo tenía pactada una reunión bilateral con el mandatario estadounidense, por lo que tuvimos que ir al hotel que albergaba solo a la delegación de ese país. Hice una crónica relatando las extremas medidas de seguridad que incluyeron hasta la revisión del maquillaje que portaba. (Anexo 13) (21 octubre 2001)

-¿Porqué no te callas? Santiago de Chile: La XVII Cumbre Iberoamericana transcurría esta vez con una novedad. Las sesiones de los presidentes que usualmente eran reservadas - por lo que era necesario acudir a fuentes confiables para reconstruir lo esencial- podían verse y escucharse en directo. Fue gracias a ello que pudimos ser testigos en vivo y en directo cómo el rey de España, Juan Carlos I, le espetó airadamente al gobernante venezolano Hugo Chávez: “¿Por qué no te callas?”. Chávez había colmado la paciencia de los presentes con su largo discurso y sus frases ofensivas hacia el ex jefe de gobierno español José María Aznar y a las empresas españolas. Luego del incidente, el rey abandonó la cumbre y fue cortada la transmisión en vivo con las discusiones de las autoridades presentes. (Anexo 14) (11 noviembre del 2007)

-Entrevista a Hugo Chávez. Bariloche. En más de una ocasión, cuando viajaba a cumbres presidenciales, por mi cuenta trataba de identificar el hotel donde se iba a realizar el evento y ahí me hospedaba. Era una opción un poco cara para el diario, pero 
como yo les explicaba a mis jefes eso implicaba que la seguridad no podía retirarme del hotel -como hacían con los otros periodistas- porque yo era una huésped más. Eso me servía para obtener exclusivas como esta entrevista al paso al presidente Chávez durante una cumbre de Unasur, muy comentada porque puso en evidencia su hipocresía comercial. (Anexo 15) (30 de agosto del 2009)

-Avión parrandero: Era el mediodía del sábado y la Cumbre Iberoamericana que se realizaba en Viena estaba llegando a su fin. Partí raudamente al centro de prensa para escribir sobre los acontecimientos de la mañana. Según mis cálculos, tenía menos de una hora porque luego debíamos estar listos para abordar el avión y retornar a Lima. Mi apuro era mayor porque le había prometido a mi hija Lucia de 7 años que esta vez sí íbamos a pasar el día de la madre juntas. "Volamos toda la noche y llego temprano por la mañana a casa", pensaba sonriente. Pero todo cambió. Nos anunciaron que ya no regresaríamos a Lima hasta el martes de la siguiente semana. El presidente Toledo había decidido reunirse con la "colonia peruana en Málaga" (sic) y el lunes sostener una reunión en Madrid con el rey Juan Carlos.

Terminamos así en una playa de Málaga con el pretexto de la mentada reunión con la colonia nacional. A los periodistas nos despacharon a un hotel alejado del presidencial con vista a una autopista, pero cometieron el error de que el bus que nos recogió al día siguiente para trasladarnos al aeropuerto hizo una parada para recoger a los diplomáticos y miembros de la comitiva que habían pasado el fin de semana con Toledo en un lujoso hotel frente a una exclusiva playa malagueña. La condición en la que subieron fue lamentable. El almuerzo había estado más que alegre, la borrachera era inocultable, todo alentado por el presidente. Los cánticos de "Pásame la Botella" nos acompañaron todo el viaje. A partir de ahí al avión presidencial se lo conoció como el 'avión parrandero'. (Anexo 16) (16 de mayo del 2006)

-Terremoto de Pisco.: Muy temprano por la mañana me recogió una unidad móvil para partir a Pisco, donde se había sentido con mayor fuerza el terremoto. Nos habían informado que el presidente iba a viajar a Pisco. El chofer que me asignaron era uno de los más experimentados. Fue gracias a él y a su pericia que encontramos una ruta, ya cerca de Pisco, que nos dejó a pocas cuadras de la Plaza de Armas. Periodísticamente hablando eso fue una gran suerte. Pero personalmente fue uno de los momentos mas 
dolorosos de mi carrera. Y es que habíamos llegado antes que muchos familiares, quienes se habían quedado atascados en la carretera. Los cuerpos, apenas cubiertos, estaban colocados uno al lado del otro en la plaza. Y seguían llegando. Poco a poco empezaron a acercarse padres, hermanos, hijos, tíos a reconocer a sus seres queridos. Los gritos de dolor y los llantos desconsolados se fueron repitiendo hora tras hora. Esa tarde escribí mi nota sollozando. Al llegar a mi casa de madrugada solo quería abrazar a mi hija y seguir llorando. La tristeza me duró varios días. (Anexo 17) (17 de agosto del 2007)

\subsection{El litigio Marítimo Perú-Chile}

La cobertura del litigio marítimo entre el Perú y Chile fue la más extensa de mi carrera. Se extendió desde el 2004 hasta el 2014.

En el 2004 el Perú logró que quedara por escrito, vía una nota diplomática, que existía una diferencia entre ambos países sobre la delimitación marítima. Para Perú no teníamos límite, mientras que para Chile no había nada que discutir. Recuerdo haber entrado de un momento a otro a utilizar términos como líneas de bases, coordenadas, mapas cartográficos y una nomenclatura jurídico-diplomática bastante complicada. Me di cuenta de que si iba a involucrarme en el tema tenía que aterrizar el duro lenguaje jurídico y diplomático en un lenguaje periodístico asequible al lector. Aquella fue la tarea más extenuante: traducir a un lenguaje sencillo los argumentos jurídicos y técnicos sin tergiversarlos. También fue complicado lograr que los diplomáticos se mostraran dispuestos a dar información. Para ellos todo era reservado. Poco a poco me involucré en este tema. Aquí algunos de los reportes que elaboré:

-Suplemento La Haya: Antes de partir a cubrir durante 15 días la fase oral del litigo marítimo en el Palacio de la Paz en La Haya, El Comercio coordinó con El Mercurio (Chile) la publicación de una edición conjunta de tal manera que en un solo suplemento -que se publicó el mismo día en cada país- se plasmara la posición que cada uno llevaba a La Haya. 
Recuerdo haberle dicho al diagramador José 'Pepe' Blanco: “Si escribo la nota así, todo de corrido, no me va leer ni mi papá". Me ayudó a preparar una maqueta (donde se vaciaba la información) con un esquema didáctico separado por temas. El día de la publicación recuerdo que algunos amigos periodistas chilenos me dijeron que el contraste en lo que se refería a la presentación había sido muy marcado. La presentación de la posición del Perú había sido bastante clara y fácilmente internalizada por todos.

El suplemento también incluía información útil elaborada por otros colegas del diario sobre lo que iba a ocurrir en esos 15 días de sesiones. (Anexo 18) (24 de noviembre del 2012)

La Fase oral: Durante 15 días desde La Haya (Holanda) reporté las audiencias que se desarrollaron en el Palacio de La Paz sede de la Corte de Justicia Internacional. Los mejores abogados del mundo elegidos por el Perú y Chile presentaban los argumentos ante los jueces del máximo organismo judicial de las Naciones Unidas, apoyándose en mapas, citas y documentos históricos. Todo era presentado en inglés o francés idiomas oficiales en la corte. Yo grababa las presentaciones e iba apuntando los minutos exactos donde podía extraer alguna cita. Además iba tomando nota a mano de lo que me parecía lo más relevante.

Fue extenuante porque los términos jurídicos usados por los abogados eran en ocasiones ininteligibles para una periodista como yo sin estudios en derecho internacional. A veces, luego de largas horas de presentaciones acudía a los especialista de la Cancillería para que me descifraran algunos términos. Alejandro Neyra diplomático y amigo era uno de los que me apoyaba. La delegación estaba demasiado ocupada con los abogados preparando las réplicas a lo que los abogados chilenos iban planteando por lo que era difícil contactarlos. A veces por teléfono rápidamente absolvían alguna duda.

Felizmente el cambio de horario jugó a mi favor porque hacia que mis días fueran de 18 o 20 horas. Cuando empezaban las audiencias alrededor de las nueve de la mañana en La Haya, en Lima eran las tres de la madrugada. Y cuando en Lima estaban en la efervescencia del cierre de edición - justo cuando me pedían algunas precisiones, 
ampliaciones o reducciones a mis notas- eran las dos o tres de la mañana en La Haya. Dormía cuatro horas con suerte, pero fue una experiencia inolvidable.

Me sorprendió la relevancia que le daban a los periodistas de prensa escrita. En el Gran Salón de la Justicia donde se desarrollaban las audiencias, estaban los 15 jueces de un lado y al frente de ellos un bloque de bancas para la delegación peruana y sus abogados $\mathrm{y}$ otro bloque de bancas para la delegación chilena. $\mathrm{Y}$ a un costado, entre los jueces y las delegaciones, es decir en un privilegiado lugar para poder observar las audiencias se ubicaban tres periodistas de prensa escrita. Un cupo fue para el Perú, que tomé yo y otro para Chile. Fueron decenas de notas las que escribí desde La Haya durante esos quince días. Aquí una pequeña muestra (Anexo 19) (4, 5 y 7 de diciembre del 2012)

\section{-Perú y Ecuador sellaron sus límites marítimos}

Guardé el secreto por lo menos durante seis meses. Me había enterado casualmente que el Perú y Ecuador estaban negociando su tratado de límites marítimos. Era vital en ese momento para el proceso que el Perú seguía con Chile en la Haya. Tenía la noticia de la negociación y algunos detalles pero desde la cancillería me pidieron que por favor no revele nada hasta que el acuerdo estuviera firmado porque si se hacia público podían frustrarse las negociaciones. Recuerdo que lo comenté con mis jefes y decidimos que por tratarse de un tema de Estado en el que estaba involucrada la posición peruana en un litigio internacional podíamos esperar. Confieso que me costó hacerlo. Era una primicia pero entendí que en este caso primero estaban los intereses de mi país. Se publicó la información cuando la negociación diplomática concluyó. (Anexo 20) ( 3 de mayo del 2011)

-Lectura de la sentencia: “¿Cecilia, quieres ir a La Haya, a Santiago o quedarte en el diario?" "Quiero ir a La Haya", le respondí a Fritz Du Bois, en ese entonces director de El Comercio. Lo que ocurría es que la lectura iba ser relativamente rápida -en una tardey en ese entonces los gastos de viaje ya empezaban a reducirse en la redacción. Pero felizmente pude viajar a escuchar lo que -después de 10 años de haber oído por primera vez hablar de la corte de La Haya y de haber escrito decenas de artículos- habían decidido los jueces. La crónica la escribí desde allá mientras que el desglose de la sentencia se elaboró en Lima. 
Conté por ejemplo cómo se pasaban 'papelitos' durante la larga lectura de sentencia y la indicación de Allan Wagner de poner cara de póker, es decir, no mostrar ninguna emoción durante la lectura. En ese entonces, El Comercio lanzaba con fuerza su twitter institucional y con mis reportes desde La Haya se logró un récord en menciones. (Anexo 21) (28 de enero del 2014)

\section{LECCIONES APRENDIDAS}

Desde que empecé a hacer periodismo y hasta el último de mis días en El Comercio había un momento muy especial en el trabajo que realizaba diariamente.

Ese momento llegaba luego de la cobertura del hecho (conferencias, ceremonias, viajes), a veces tras largas horas buscando información, escuchando discursos, desgrabando algunas entrevistas clave y consiguiendo y revisando documentos.

Era el momento cuando sentía que podía empezar a escribir. Hacía una pausa y me preguntaba mirando mis notas en la computadora: ¿Dónde está la noticia? ¿Cuál es? (en el sentido mas puro de la acepción) ¿Qué es lo que ha ocurrido hoy? ¿A cuántos afecta? ¿Es útil? ¿Genera indignación? ¿Es un cambio de rumbo? ¿Es un hecho nuevo? (una revisión de lo publicado en torno al tema era obligatorio), y lo más importante: ¿Tengo elementos suficientes y corroborados para construir la historia?

A veces no era tan sencillo, sobre todo cuando tenías que analizar el mensaje de varios actores o había obtenido la información gracias al 'cuchareo', bendita técnica periodística a partir de la cual logré muchas primicias. "Cecilia es nuestra especialista en cuchareo", me decía siempre entre risas un experimentado y buen amigo periodista. El arte del 'cuchareo' no es más que hablar con las personas adecuadas, usualmente por teléfono, de manera informal y tener el olfato periodístico para detectar dónde puede haber noticia. Cuando los gastos de la redacción empezaron a reducirse nos asignaron 
un código para las llamadas. Recuerdo que una vez rompí el récord de la llamada más larga. El nombre de la fuente solo se lo reporté a mi editor.

Mi editor era imprescindible, sobre todo para los momentos de sequía informativa. Llevar un tema e intercambiar puntos de vista sobre dónde estaba la noticia era otra manera de encontrar el nirvana de la información.

Una vez que tenía claro cuál era la noticia, empezaba y sin respirar prácticamente llegaba a la última línea. Para mí era una catarsis escribir cada artículo. No tenía paz hasta que no ponía el titular preciso con las palabras exactas. Sentía la necesidad de contar lo que había visto y oído. Luego de ese primer borrador, que normalmente surgía a borbotones, empezaba la revisión y edición. Una, dos y hasta tres veces 'limpiaba' mi texto.

La paz llegaba cuando enviaba la nota a mi editor y esperaba sonriente las sugerencias para eventualmente realizar correcciones y regresar a casa.

Yo era una periodista que hacía calle. Usualmente entregaba mis notas en el día. Rara vez hice periodismo de investigación. Lo mío fue el reporte y el análisis de hechos políticos. Mis fuentes Palacio de Gobierno, Cancillería, ministros de Estado y cualquier funcionario público que tuviera algo que contar del Ejecutivo. Todas las fuentes, independientemente del cargo que ejercían, eran valiosas en el momento adecuado.

Una de mis obsesiones cuando abordaba temas complicados era que todos entendieran lo que estaba escribiendo. Que el mensaje técnico, jurídico o político fuera claramente decantado. "Si no escribo bien no me va a leer ni mi papá", era una de las frases que me gustaba repetir.

En los 20 años que pasé en el diario siempre había alguna crisis política. Todos los días sentía que empezaba a subir una montaña, llegaba a la cima y finalmente te ibas a casa. Pero al día siguiente todo volvía a empezar. Me ayudó mucho en esos años que el alboroto estaba de la puerta hacia afuera. Adentro, en el equipo de política, las funciones y responsabilidades estaban claras. $\mathrm{O}$ al menos así yo lo sentía. 
Ayudaba mucho la serenidad de Juan Paredes Castro, el editor central de política. No había crisis constitucional, cambio de gabinete o lo que fuera que no los asumiera con serenidad y bonhomía. Eso se transmitía al equipo.

Una de las reflexiones de estos 20 años de periodismo tiene que ver con la imparcialidad.

¿Los periodistas somos imparciales?

No. Como seres humanos, nuestras emociones están presentes. Sin embargo, estamos obligados a intentar ser imparciales en todo momento. Separar nuestros sentimientos, simpatías o antipatías al escribir o dar una información es una tarea agotadora. Es fácil decirlo pero no ejercerlo. Reconozco que en más de una ocasión estuve a punto de perder la paciencia pero me contuve.

Recuerdo que en el Manual de Estilo del diario El Comercio estaba por escrito que los periodistas no podíamos ser militantes de ningún partido ni organización. Es cierto que en ocasiones he tenido al frente a personajes cuestionados. En política siempre ha habido buenos y malos personajes que podían cambiar de roles en cualquier momento. Y también buenas causas que van fluctuando en intensidad: luchar contra el terrorismo, luchar contra la depredación del medio ambiente, luchar contra la violencia contra la mujer, etc. Causas que a veces son cíclicas -van y vienen en la coyuntura informativapero como periodista mi papel no era hacer activismo, por más bienintencionada que fuera la causa. Mi deber era reportar los hechos en el momento tal como se presentaban e intentar presentar las dos partes, o contrastar los discursos.

En mi opinión, los buenos periodistas no deben ser identificados con ninguna tendencia política, religiosa, temática (medio ambiente, feminismo, etc). Esa es la tarea más difícil de todas. Reportar todas las posiciones así sintamos repulsión o simpatía por lo que oímos o vemos.

El periodista reporta lo que los activistas expresan, piensan e impulsan. Si cruzas la línea y te conviertes en activista de una causa -por más buena que esta sea-, mejor cambia de carrera. 


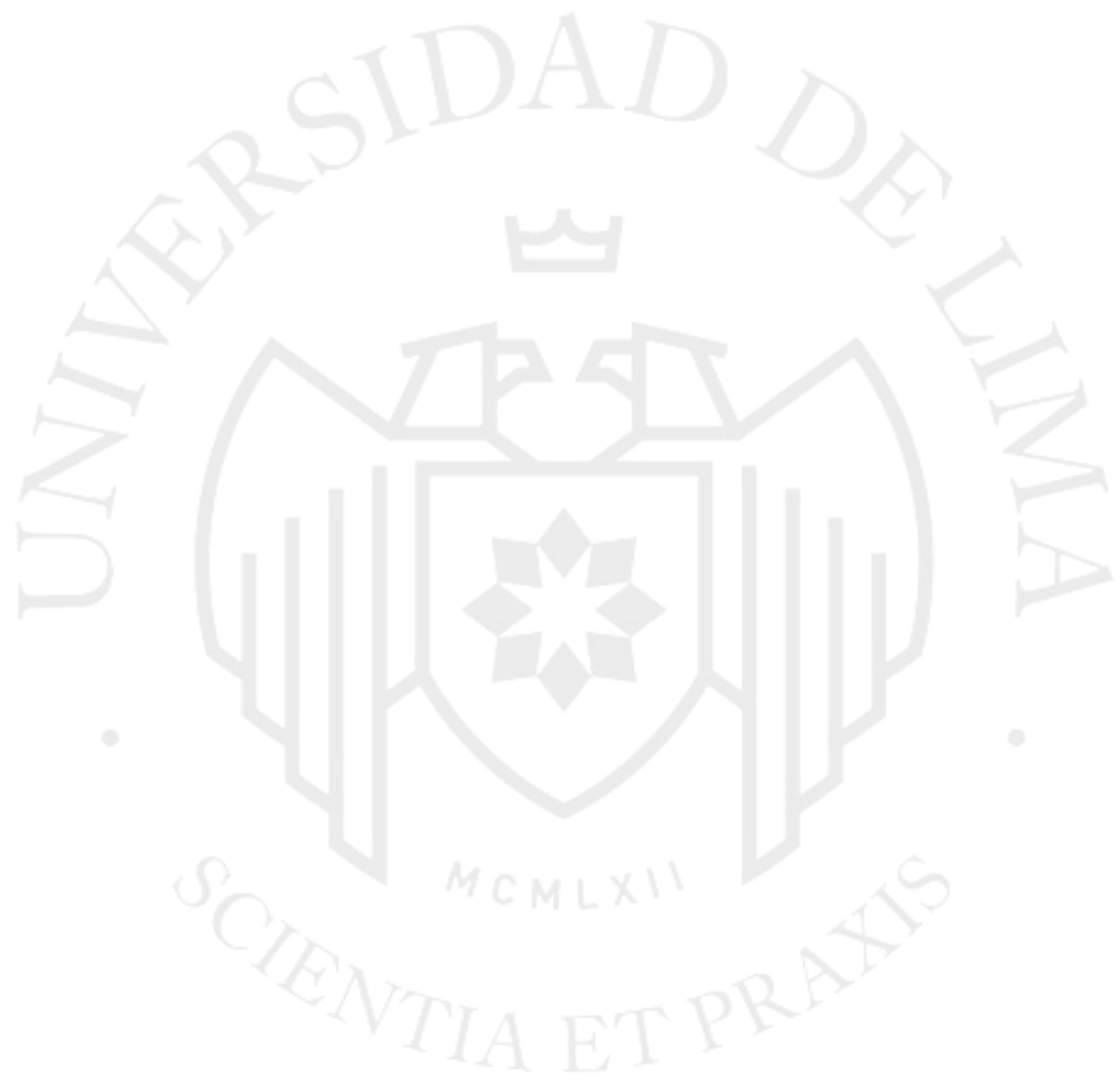




\section{REFERENCIAS}

1. Wolf, T. (1998). El Nuevo periodismo (7th ed.). Barcelona: Anagrama.

2. Vargas Llosa, M. (1993). El pez en el agua. Barcelona: Seix Barral.

3. Capote, T. (2016). A sangre fría. Barcelona: Anagrama.

4. Jochamowitz, L. (1997). Ciudadano Fujimori. Lima, Perú: PEISA.

5. Manual de Estilo. (2019). Disponible en :

http://www.grupoelcomercio.com/index.php/manual-de-estilo

6. Principios Rectores | El Comercio Perú. (2019). Disponible en : https://elcomercio.pe/principios-rectores 


\section{ANEXOS}

Anexo 1. Helicóptero-Fujimori

Anexo 2. Montesinos

Anexo 3. Rehenes MRTA

Anexo 4. Destitución Magistrados del Tribunal Constitucional

Anexo 5. Entrevista Valentín Paniagua

Anexo 6. Anatolio Toledo

Anexo 7. Informe Comisión de la Verdad

Anexo 8. Alan García y su hijo

Anexo 9. Audiencia Benedicto XVI

Anexo 10. La Gran Transformación

Anexo 11. De Guayaquil a Shangái

Anexo 12. Cambios en la ruta

Anexo 13. Reunión con Bush

Anexo 14. Porqué no te callas

Anexo 15. Entrevista a Hugo Chávez

Anexo 16. Avión Parrandero

Anexo 17. Terremoto de Pisco

Anexo 18. Suplemento La Haya

Anexo 19. Fase Oral

Anexo 20. Perú-Ecuador

Anexo 21. Sentencia La Haya 


\section{Anexo 22. Hoja de vida Documentado}

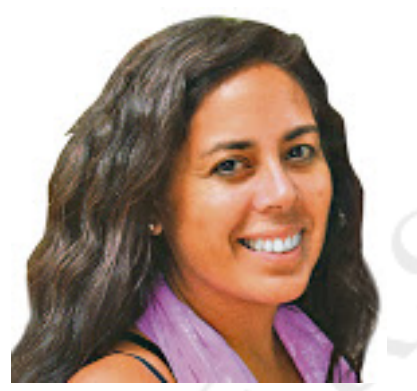

Martha Cecilia Rosales Ferreyros

Cel. 998859455

Código:861786

chichirosalesf@gmail.com

Periodista con más de 20 años de experiencia en cobertura, análisis y presentación de la realidad política. Habilidad para transformar mensajes jurídicos y técnicos en textos periodísticos. Facilidad para trabajar bajo presión y adaptarse a diversos escenarios y personalidades. Habilidad para diseñar e implementar estrategias de comunicación externa, interna y digital.

\section{Experiencia Laboral}

Dic 2017- Set 2018

Universidad César Vallejo

Directora de Imagen Institucional

(Comunicación Corporativa )

Responsable de la Comunicación Externa,

Interna

y Digital

Oct 2016 - Mar 2017

Willax Televisión

Programa de Cecilia Valenzuela "Mira Quién Habla"

- Elaboración de Reportajes, Apoyo en Producción, Co-conducción, Edición Periodística, Promoción del programa.

https://www.youtube.com/watch?v=nr2eMrqELIE https://www.youtube.com/watch?v=CZeOBOq-iHU

https://www.youtube.com/watch?v=elHafe-9wRo

https://www.youtube.com/watch?v=ne zdrleLas

https://www.youtube.com/watch?v=2QxzQP1bo_I

(entre otros) 
Abr 1995 - Jun 2015

Diario El Comercio

Periodista - Sección Política

- Seguimiento de las actividades públicas, discursos y análisis de la gestión de gobierno de cinco presidentes: Alberto Fujimori, Alejandro Toledo, Valentín Paniagua, Alan García y Ollanta Humala.

- Cobertura de las actividades de la Cancillería de la República.

- Análisis de la política exterior del Perú (agenda bilateral, regional y multilateral)

- Cobertura de Cumbres presidenciales: APEC, Alianza del Pacífico, ALC-UE, Cumbre Iberoamericana, Unasur etc. y visitas de Estado y oficiales a diferentes países.

- Seguimiento y análisis del litigio marítimo Perú-Chile incluida la etapa preliminar a la presentación de la demanda ante la corte de La Haya, cobertura en la corte de La Haya (etapa oral y lectura de sentencia) y la ejecución post fallo (diez años).

- Cobertura de actividades del Congreso de la República (sesiones plenarias, comisiones parlamentarias, etc.)

- Participación en reuniones de editores, definición de temas periodísticos y manejo de personal.

1992

- $\quad$ Reportera de ATV Noticias

\section{Estudios}

1994

Universidad de Lima

Bachiller en Ciencias de la Comunicación

Actual

Pontificia Universidad Católica del Perú

Maestría en Ciencia Política

Inglés 


\section{Anexos}

\section{Grado de Bachiller}

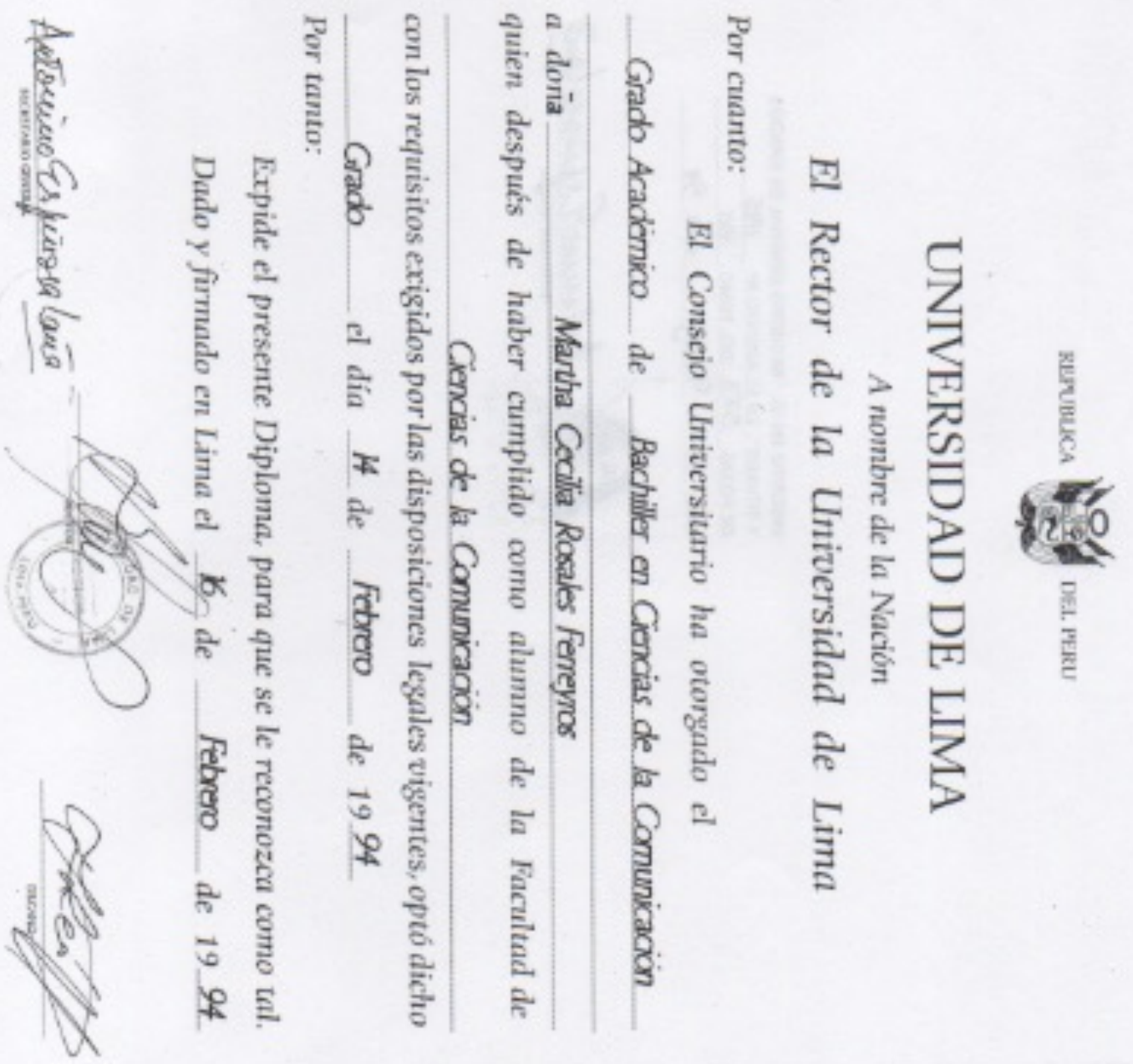




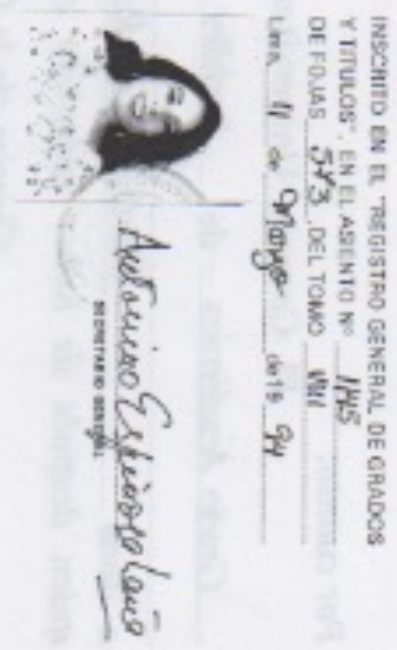




\section{Certificado de trabajo de El Comercio}

\section{El Camertio}

\section{CERTIFICADO DE TRABAJO}

Por medio de la presente certificamos que la señora ROSALES FERREYROS MARTHA CECILIA prestó servicios a esta empresa desde el 01 de Agosto de 1995 hasta el 30 de Junio de 2015 desempeñándose a la fecha como REDACTOR(A) I en el área de POLITICA (COM).

La señora ROSALES FERREYROS MARTHA CECILIA durante su trayectoria laboral en esta empresa demostró capacidad, honestidad y responsabilidad en las tareas que fueron encomendadas.

Expedimos la presente constancia a solicitud del interesado para los fines que estime conveniente.

Lima, 21 de Mayo de 2018

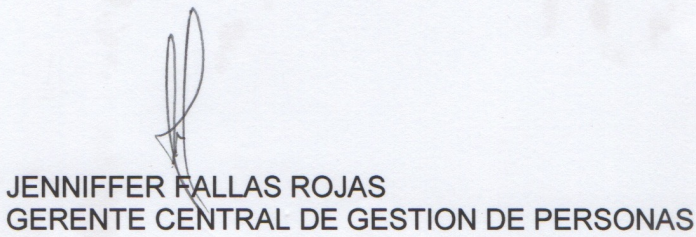

JR. SANTA ROSA 300 LIMA 20143229816 


\title{
Andina de Radiodifusión S. A.
}

\author{
CERIIFICA D O
}

B1 Drectoc Genersl de Andine de Radiodtfusico XIV S.A., Canal 9, quian sucribe:

\section{CEIIFICA}

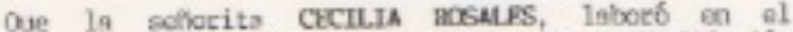
Departanento de Pronsa de Aaxtina de iladiodifusión S.A. , desde fines de Enero a Julio de 1992, con el cargo de lapportere para "ATV voliciAs".

La seforita Rosales, durante el tiempo que trabaj6 en este Cansl, ha denostrade ser una excelente profesionsl, con gran doricación al trabejo, buer cornportasiento y gran esplefitu de colaboracióc.

Se exticrda el pcesente certificsto a solicitud de la intereseds pors loc fines que estime conveniente.

\section{Atentarrente,}

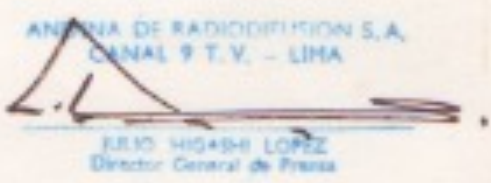

JH/et. 
Certificado de trabajo de la UCV

Universidad César vallejo

\section{CERTIFICADO DE TRABAJO}

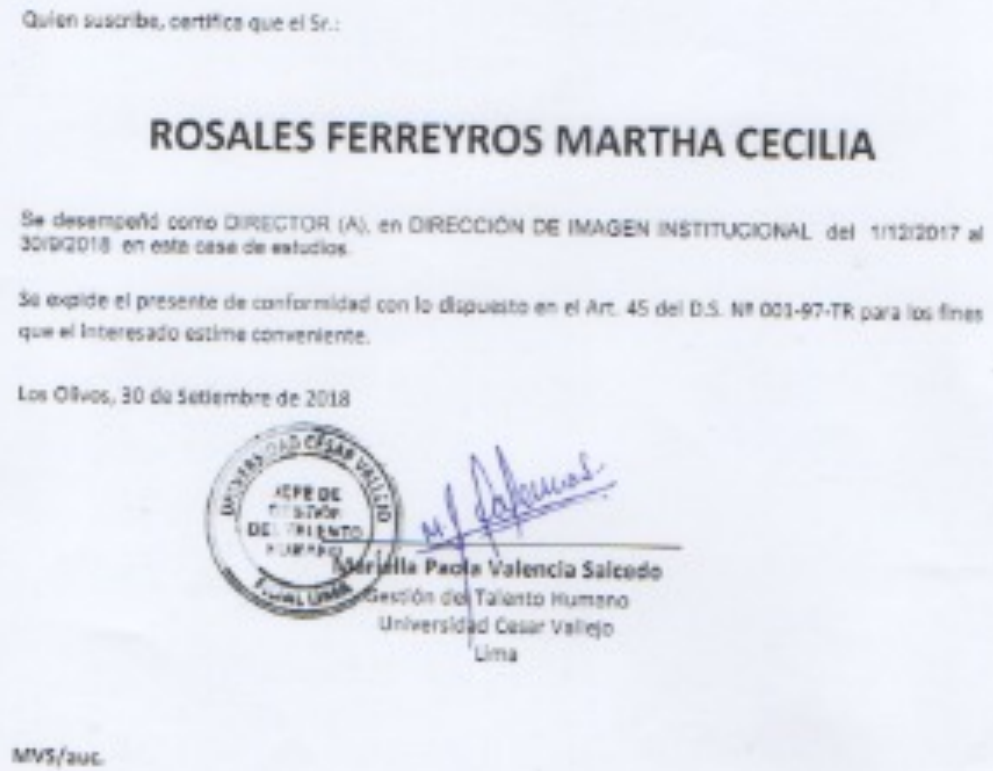


Talleres, Seminarios y Premios

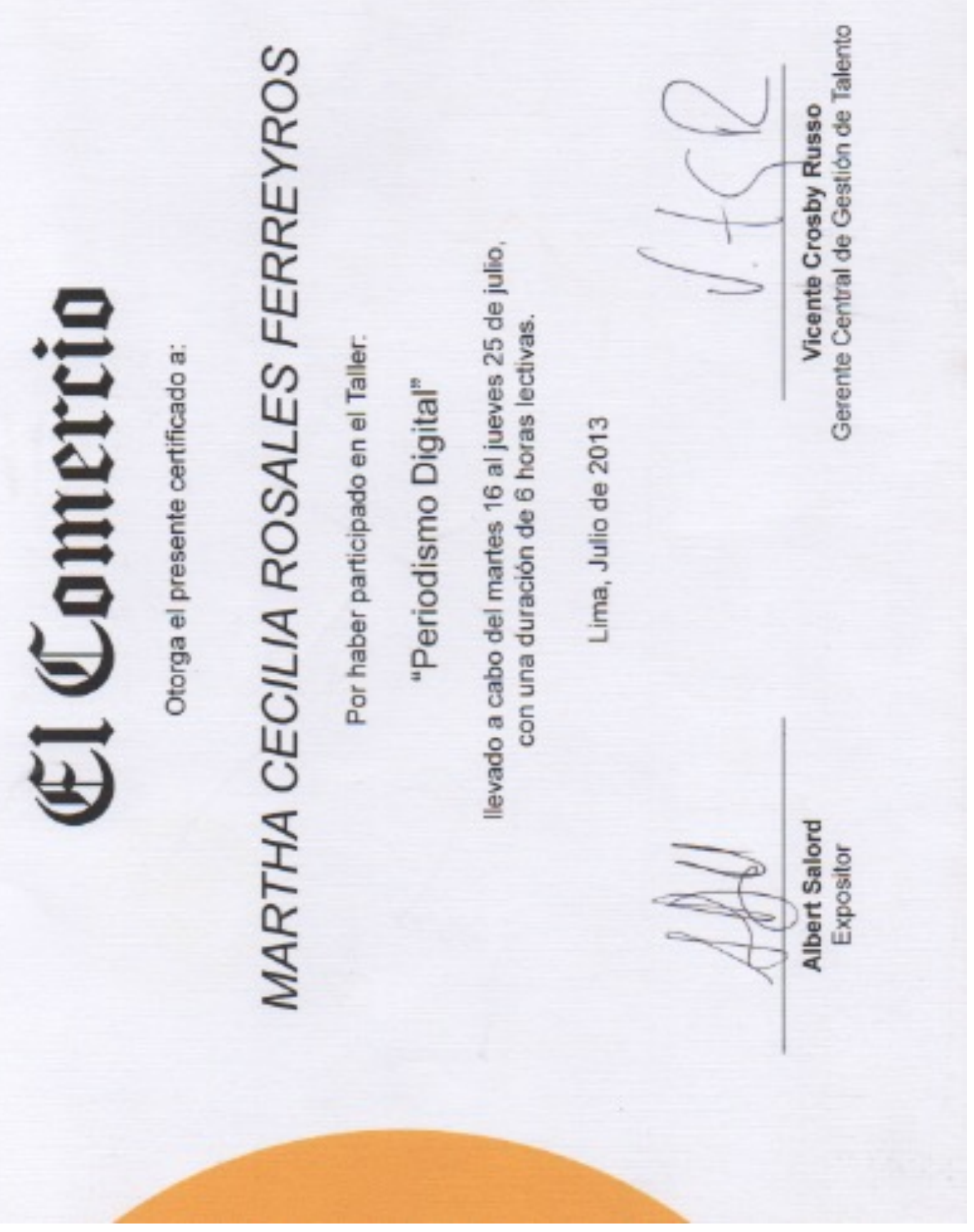




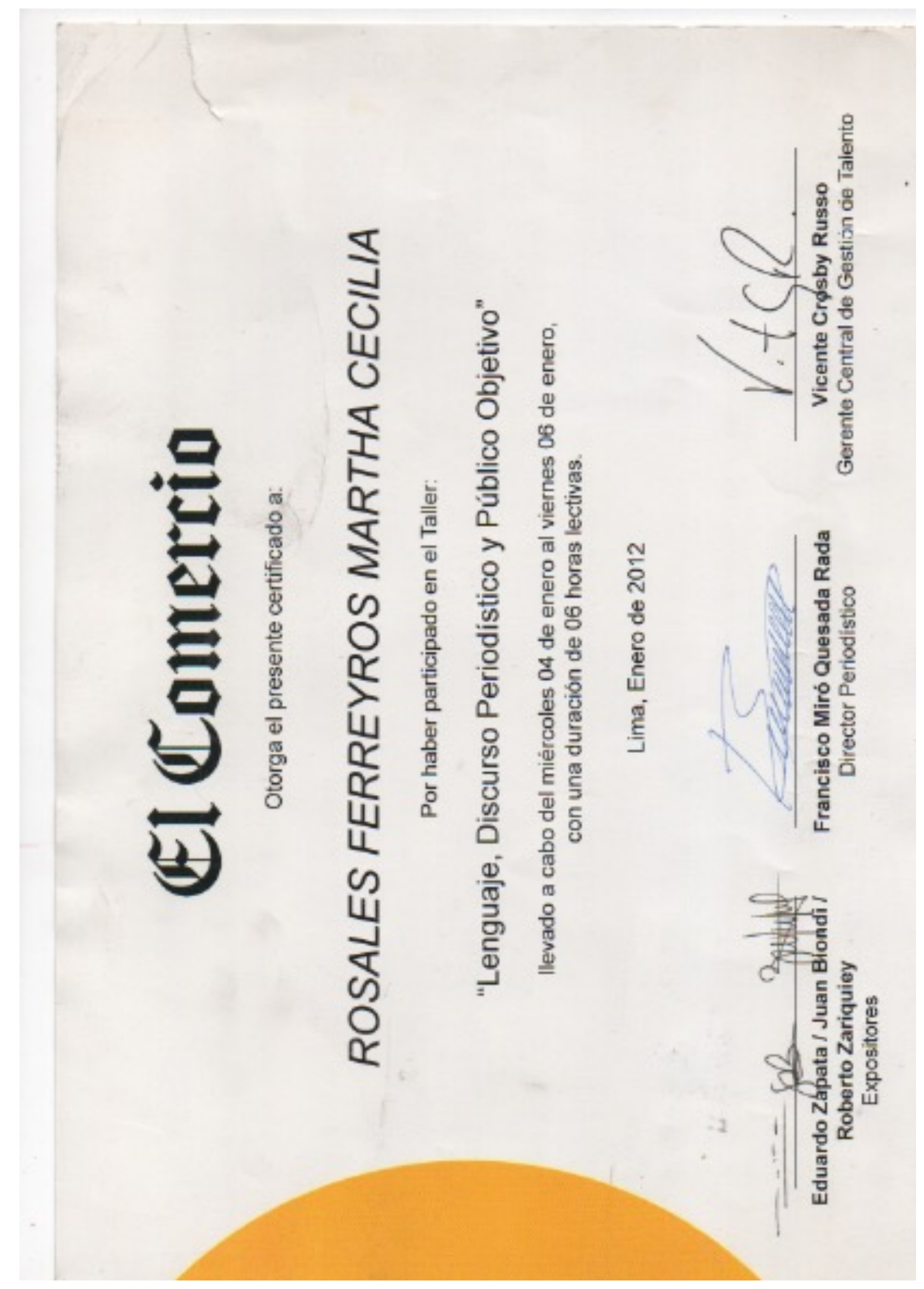




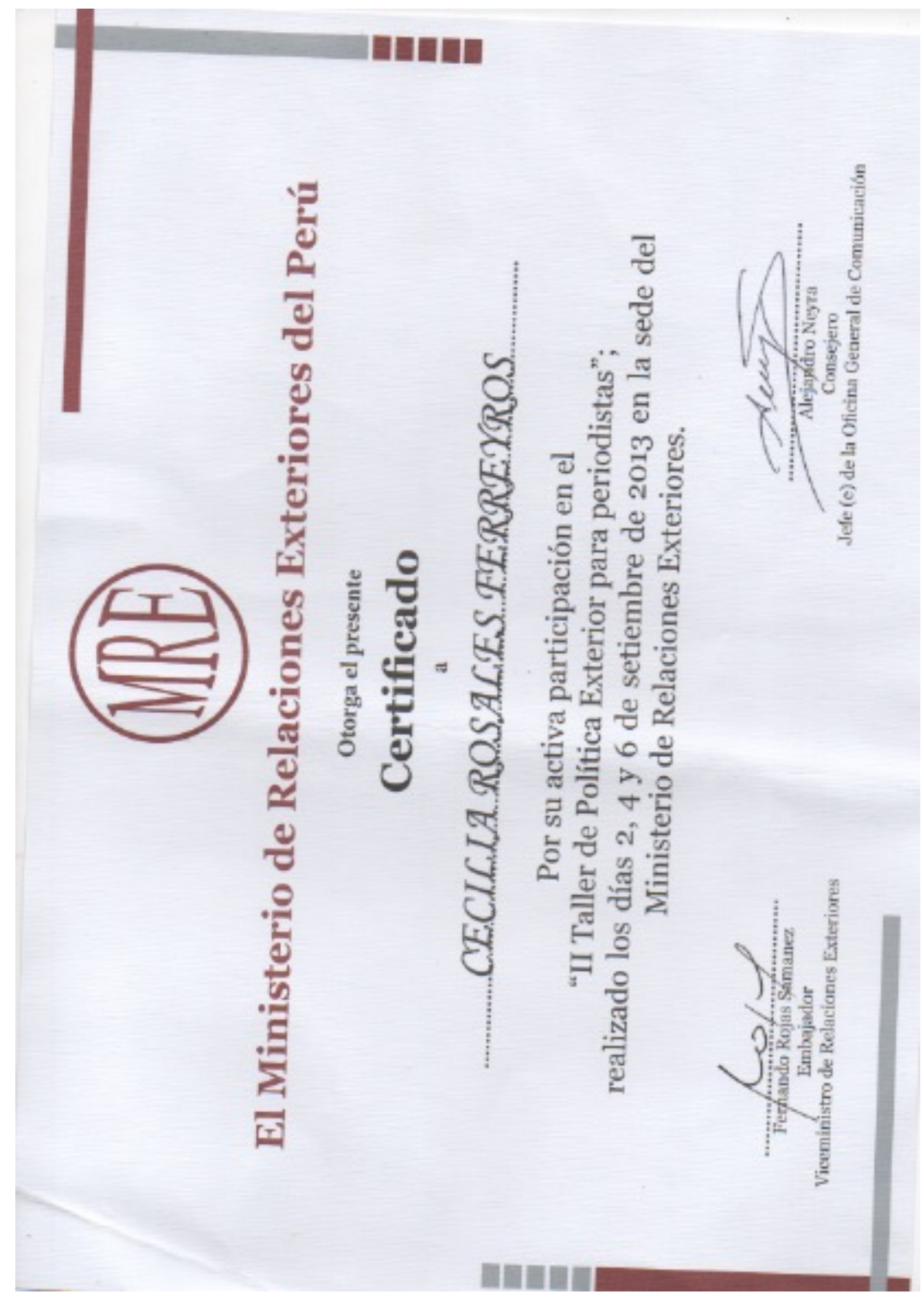




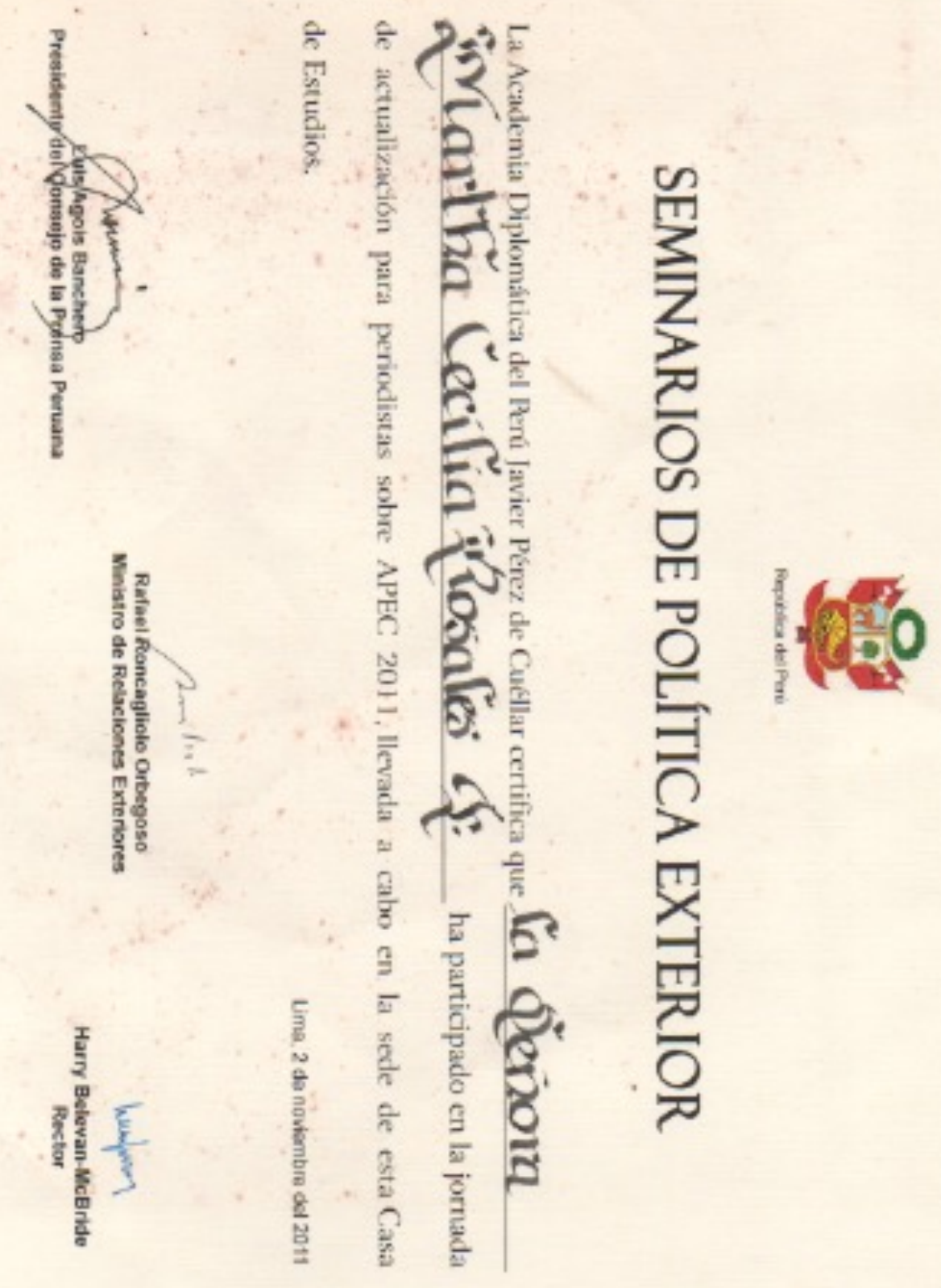




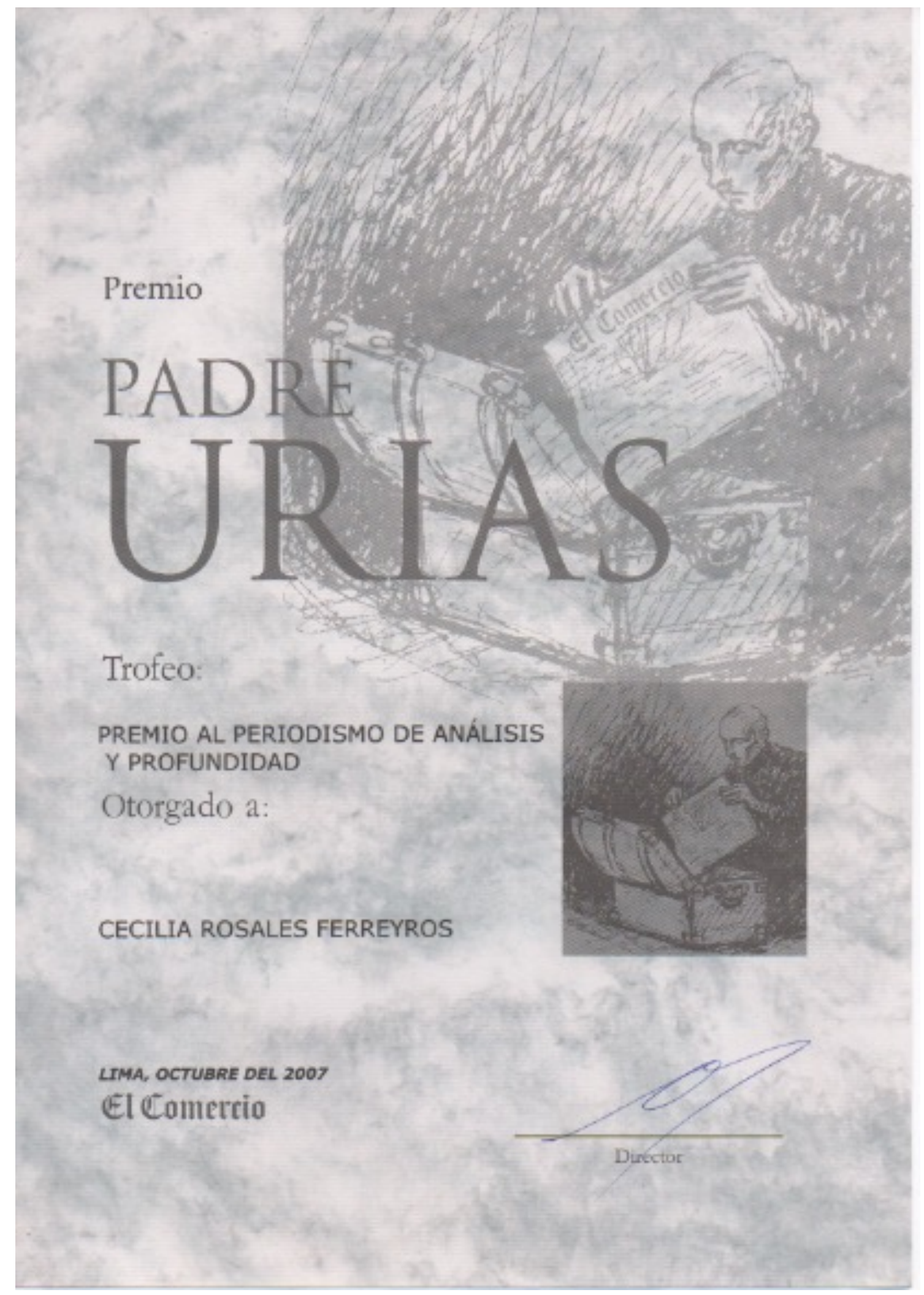




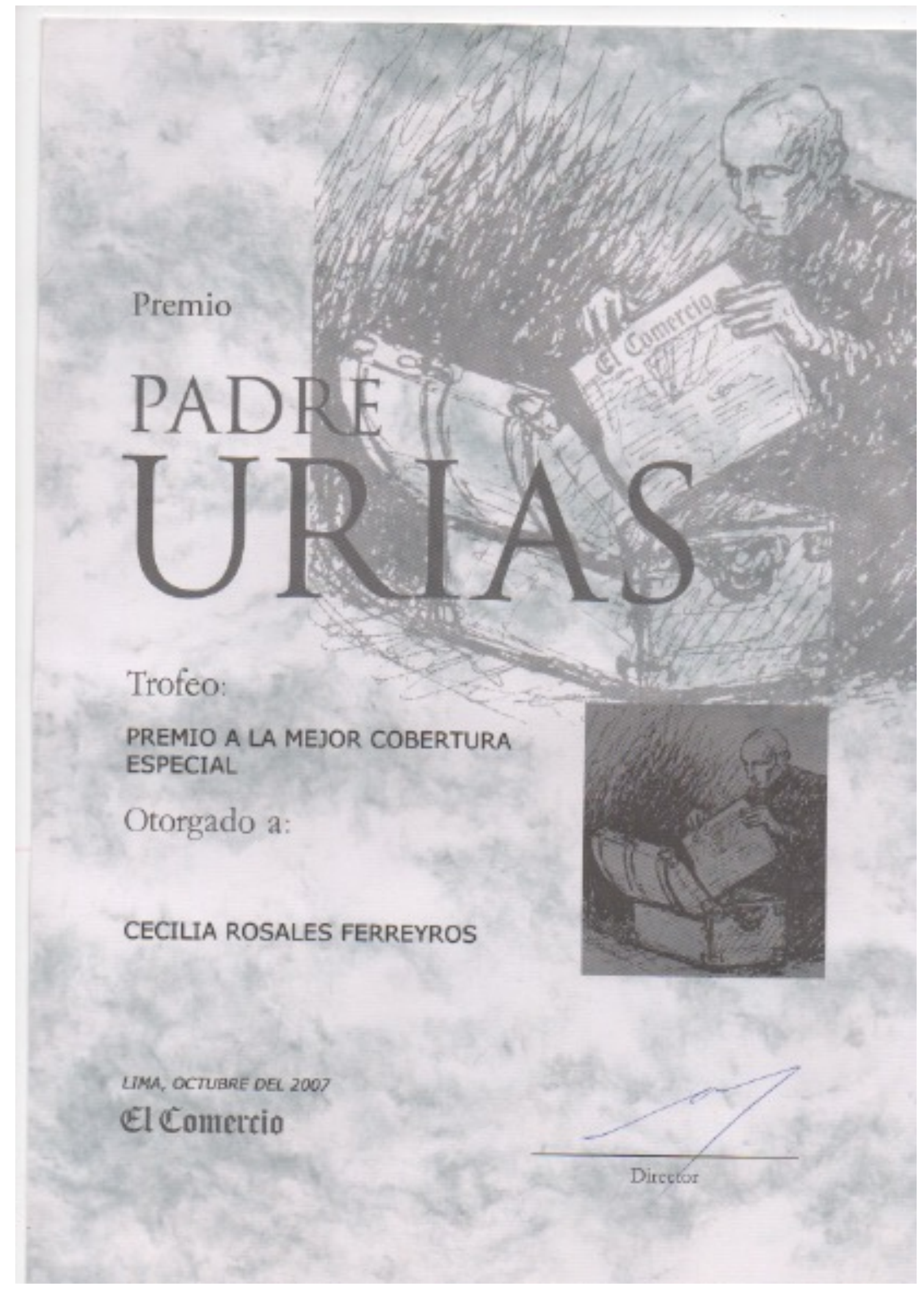


Premio

\section{PADRE}

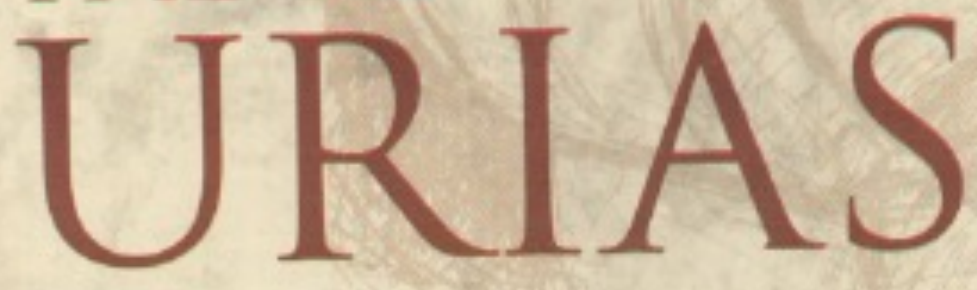

Trofeo:

\section{Premio Espadachín}

Otorgado a:

Cecilia Rosales

Ferreyros

\section{El Comercio}

lima. $1^{\circ}$ de cctubre de 1996
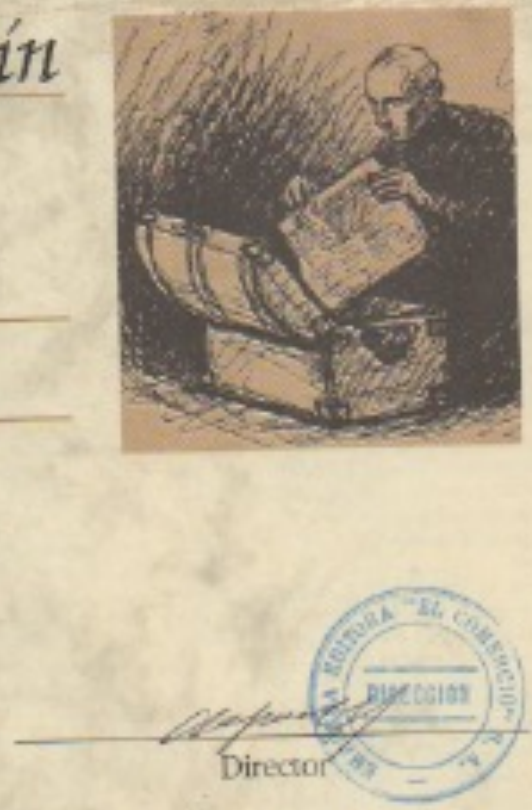


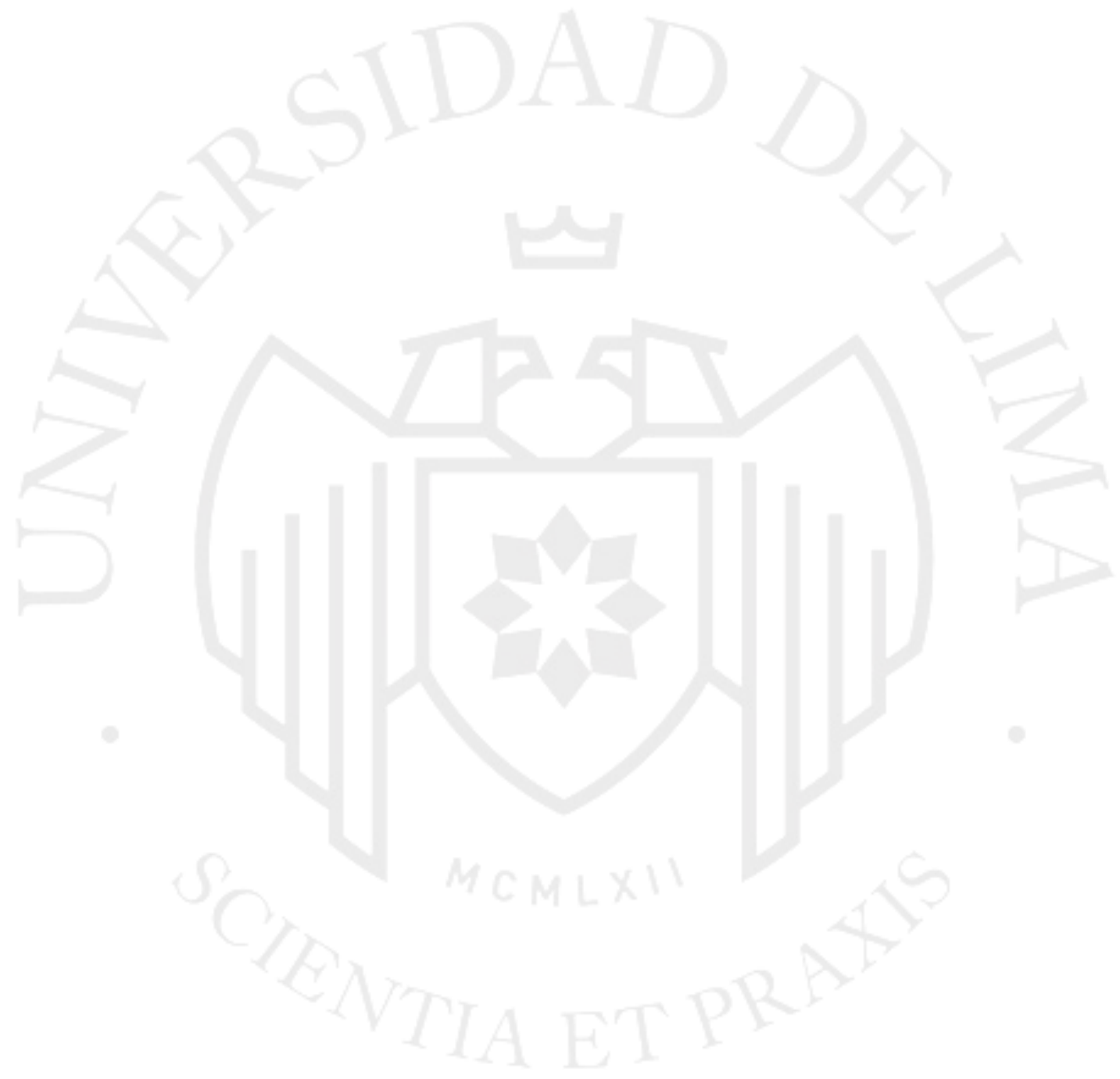

